\title{
Blood Eosinophil Counts in Chronic Obstructive Pulmonary Disease: A Biomarker of Inhaled Corticosteroid Effects
}

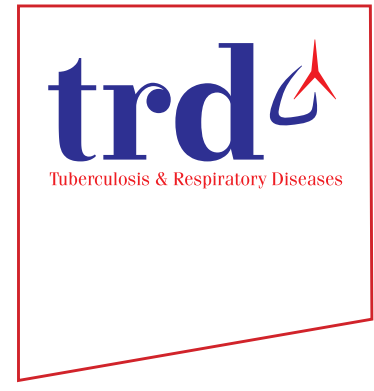

\author{
Dave Singh, M.D. \\ Division of Infection, Immunity \& Respiratory Medicine, University of Manchester, Manchester University NHS Hospital Trust,
} Manchester, UK

Blood eosinophil counts have emerged as a chronic obstructive pulmonary disease (COPD) biomarker that predict the effects of inhaled corticosteroids (ICS) in clinical practice. Post-hoc and prospective analysis of randomized control trials have shown that higher blood eosinophil counts at the start of the study predict a greater response to ICS. COPD patients with frequent exacerbations (2 or more moderate exacerbations/yr) or a history of hospitalization have a greater response to ICS. Ex-smokers also appear to have a greater ICS response. Blood eosinophil counts can be combined with clinical information such as exacerbation history and smoking status to enable a precision medicine approach to the use of ICS. Higher blood eosinophil counts are associated with increased eosinophilic lung inflammation, and other biological features that may contribute to the increased ICS response observed. Emerging data indicates that lower blood eosinophil counts are associated with an increased risk of bacterial infection, suggesting complex relationships between eosinophils, ICS response, and the airway microbiome.

Keywords: Biomarker; Chronic Obstructive Pulmonary Disease; Eosinophils

\section{Introduction}

Chronic obstructive pulmonary disease (COPD) is characterized by irreversible airflow obstruction and persistent airway inflammation caused by the inhalation of noxious particles, commonly from cigarette smoking ${ }^{1}$. COPD is a heterogeneous condition, as the pathophysiological and clinical

Address for correspondence: Dave Singh, M.D.

Division of Infection, Immunity \& Respiratory Medicine, University of Manchester, Manchester University NHS Hospital Trust, Southmoor Road, Manchester M23 9QZ, UK

Phone: 44-0-161-946-4073, Fax: 44-0-161-946-1459

E-mail: DSingh@meu.org.uk

Received: Mar. 20, 2020

Revised: Apr. 1, 2020

Accepted: Apr. 10, 2020

Published online: Apr. 29, 2020

(c) It is identical to the Creative Commons Attribution Non-Commercial License (http://creativecommons.org/licenses/by-nc/4.0/). manifestations vary considerably between individuals ${ }^{2}$. For example, the presence and severity of emphysema shows marked variability between individuals. This heterogeneity causes different responses to pharmacological interventions.

Inhaled corticosteroids (ICS) are anti-inflammatory drugs that are commonly used to treat COPD patients ${ }^{3}$. Randomized controlled trials (RCTs) have shown that ICS combined with a long-acting $\beta_{2}$-agonist (LABA) reduce exacerbation rates and improve both lung function and quality of life compared to LABA monotherapy ${ }^{4}$. Furthermore, triple therapy consisting of ICS plus LABA plus long-acting muscarinic antagonist (LAMA) in a single inhaler also demonstrates these clinical benefits compared to LAMA/LABA combination treatment or LAMA monotherapy ${ }^{5-8}$. These RCTs were conducted in patients with a history of exacerbations; these individuals have an increased future risk of exacerbations, as the past exacerbation history is the best predictor of future risk ${ }^{9}$.

It is well recognized in clinical practice that the beneficial effects of ICS vary between patients ${ }^{3}$. Furthermore, long term ICS treatment has the potential for adverse effects, including osteoporosis, pneumonia, and cataracts ${ }^{2}$. While RCTs show an overall benefit for ICS on a population basis (in patients with a history of exacerbations) $)^{4}$, clinical practice requires an 
individualized approach to the use of these drugs, in order to identify individuals more likely to gain benefit while also limiting the potential for harm ${ }^{2,3}$

Precision medicine combines individual clinical and biological information to enable a more personalized approach to pharmacological treatment, with the aim of identifying patients most likely to benefit while also minimizing the risk of causing harm². Blood eosinophil counts have emerged as a COPD biomarker that can be combined with clinical information to enable a precision medicine approach to the use of ICS in clinical practice. This review will focus on the evidence supporting blood eosinophils as a biomarker to guide ICS use in COPD patients, and discuss practical issues regarding implementation in clinical practice.

\section{Eosinophilic Inflammation in COPD}

A number of cytokines and chemokines, including interleukin 5 (IL-5), control the maturation, trafficking, and activity of eosinophils ${ }^{10}$. Eosinophils secrete various proteins that promote inflammation and tissue remodeling. Studies have reported that COPD patients have increased numbers of eosinophils in sputum samples, broncho-alveolar lavage, and bronchial biopsies compared to healthy controls ${ }^{11,12}$; close inspection of the data shows that a subset of COPD patients have increased eosinophil numbers, while the remainder have levels similar to controls. Blood eosinophil numbers in COPD patients are also higher than age-matched healthy controls, even when patients with a history of asthma or atopy are excluded $^{13}$.

Kolsum et al. ${ }^{14}$ reported that COPD patients with higher blood and lung eosinophil counts showed numerous other pathological differences, including increased levels of biomarkers of type 2 (T2) inflammation and greater reticular basement membrane thickening. These features are also seen in patients with asthma ${ }^{15,16}$, but Kolsum et al. ${ }^{14}$ carefully excluded individuals with a history of asthma or atopy, so it would be incorrect to apply an asthma label to these COPD patients with eosinophilic inflammation. Furthermore, a study comparing COPD patients with a confirmed childhood history of asthma versus COPD patients with increased eosinophils and no history of asthma showed that the former group had more evidence of allergy and more exacerbations while displaying less eosinophilic inflammation (data shown in Table 1$)^{17}$. These data highlight that the terms "asthma" and "eosinophilic" should not be used interchangeably in COPD patients.

\section{Relationship between Blood and Lung Eosinophil Numbers}

Many studies have reported statistically significant associations between blood and sputum eosinophil counts, with weak to moderate correlation coefficients $(0.17-0.54)^{18-22}$. Factors that may negatively impact this relationship are poor quality sputum slides, probably more common in multicentre studies, and using only one significant figure for blood eosinophil counts. Studies of blood and lung eosinophil counts have shown diverse results, with both positive associations and no relationship ${ }^{14,23,24}$. Again, technical factors affecting lung eosinophil measurements may reduce the ability to observe an association. Nevertheless, Kolsum et al. ${ }^{14}$ showed clearly that COPD patients with blood eosinophil counts $<150$ cells/ $\mu \mathrm{L}$ had lower bronchial mucosa, broncho-alveolar lavage, and sputum eosinophil numbers compared to COPD patients with blood eosinophil counts $>250$ cells $/ \mu \mathrm{L}$ (Figure 1 ). Overall, most of these studies have shown associations between blood and pulmonary eosinophil counts, indicating that blood eosinophils are a biomarker that reflects the degree of eosinophilic lung inflammation.

\section{Modeling the Relationship between Blood Eosinophils and ICS Effects}

RCTs using induced sputum eosinophil counts demonstrated that COPD patients with more eosinophils had a greater forced expiratory volume in 1 second $\left(\mathrm{FEV}_{1}\right)$ improvement after corticosteroid treatment ${ }^{25,26}$. Sputum sampling for eosinophil counts is not widely available or practical in clinical prac-

Table 1. Clinical characteristics of COPD patients with AC compared to COPD patients

\begin{tabular}{|lccc|}
\hline & AC $(\mathbf{n}=\mathbf{1 4})$ & COPD (n=67) & COPD eosinophil $^{\text {high }}(\mathbf{n}=\mathbf{1 4})$ \\
\hline Exacerbations & $3(0-5)$ & $1(0-6)^{*}$ & $1(0-4)^{\dagger}$ \\
Skin prick positive to $>$ l allergen (\%) & 50.00 & $1.54^{*}$ & $7.14^{\dagger}$ \\
Sputum eosinophil (\%) & $2.5(0.5-9.3)$ & $2.6(0-16.3)$ & $7.0(3.5-15.8)^{\dagger}$ \\
\hline
\end{tabular}

Adapted from Kolsum et al. Respir Res 2017;18:73, according to the Creative Commons license BioMed Central ${ }^{17}$.

Values are presented as median (range) for exacerbations and sputum eosinophils.

Chronic obstructive pulmonary disease (COPD) patients (out of $n=67$ ) with blood eosinophil counts $>300$ cells/ $\mu \mathrm{L}$ are denoted COPD eosinophil ${ }^{\text {high }}$.

${ }^{*} \mathrm{p}<0.05$ for COPD vs. childhood asthma (AC). ${ }^{\dagger} \mathrm{p}<0.05$ for COPD eosinophil ${ }^{\text {high }}$ vs. AC. 

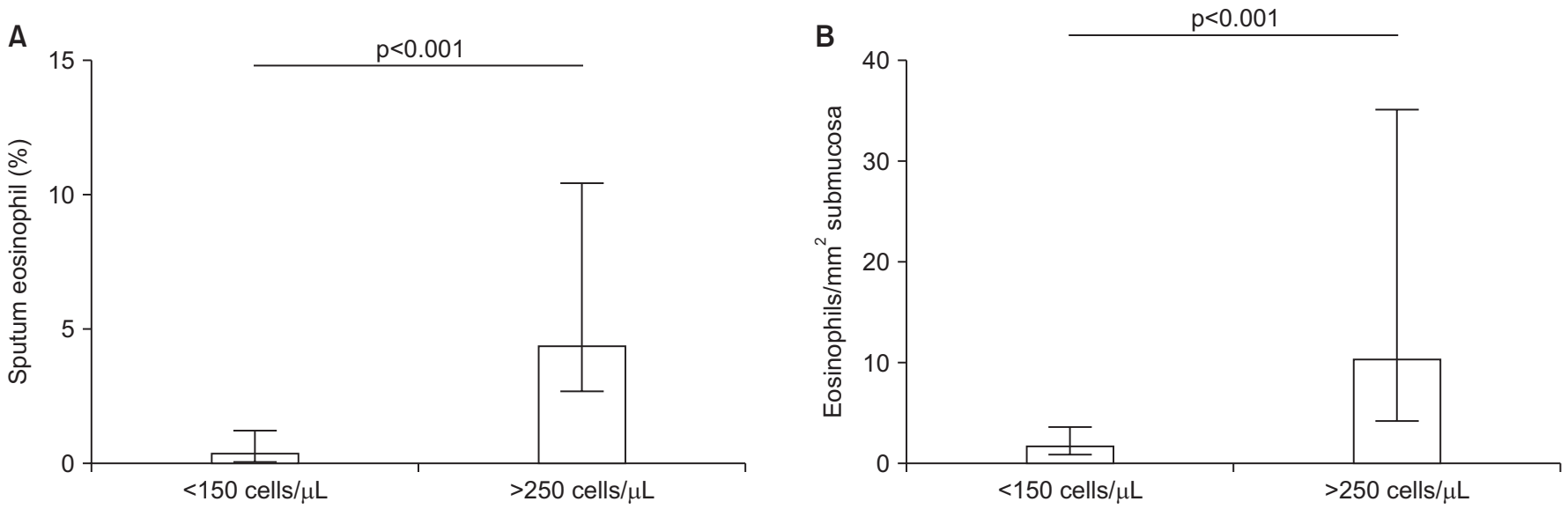

Figure 1. Chronic obstructive pulmonary disease patients with blood eosinophil counts $<150$ cells $/ \mu \mathrm{L}$ and $>250$ cells $/ \mu \mathrm{L}$. Median is shown, while error bars are interquartile range. (A) Sputum eosinophil counts (\%). (B) Bronchial mucosa eosinophil counts (per mm ${ }^{2}$ submucosa) ${ }^{14}$.

tice. Post-hoc analyses of RCTs including only COPD patients with a history of exacerbations were performed to evaluate the ability of blood eosinophil counts to predict ICS effects ${ }^{27-29}$. The effect of ICS/LABA treatment compared to LABA monotherapy on exacerbation prevention was greater in patients with higher blood eosinophil counts at the start of the study $^{27-29}$. Data modeling (the INCONTROL study; $n=4,528$ ) showed that the effect of ICS treatment was observed at above approximately 100 eosinophils $/ \mu \mathrm{L}$, with increasingly larger benefits at higher eosinophil counts ${ }^{27}$; this continuous relationship is described by Figure 2.

An important consideration for biomarkers in clinical practice is whether the results split the population in a binomial manner; this is the case for diagnostic biomarkers where a binomial categorization of "disease" or "no disease" is required. In contrast, pharmacological treatment responses form a continuous spectrum (i.e., ranging from no response to small response to large response). A biomarker for predicting drug responses should therefore predict different magnitudes of response. Using blood eosinophil counts to predict ICS "responders" and "non-responders" is a simplistic approach that does not mirror the range of clinical responses observed. Instead, the INCONTROL data modeling results show that blood eosinophil counts can be used to predict different magnitudes of response, reflecting the population distribution of drug responses ${ }^{27}$.

Pre-specified analysis of triple therapy studies conducted in COPD patients with a history of exacerbations have also reported greater ICS effects on exacerbation prevention in patients with higher blood eosinophil counts. In the IMPACT study ( $\mathrm{n}=10,333)$, data modeling showed that the benefit of triple therapy compared to LABA/LAMA on exacerbation prevent was observed at above approximately 100 eosinophils $/ \mu \mathrm{L}^{30}$. Again, the magnitude of benefit increased at higher blood eosinophil counts, with approximately $50 \%$ exacer-

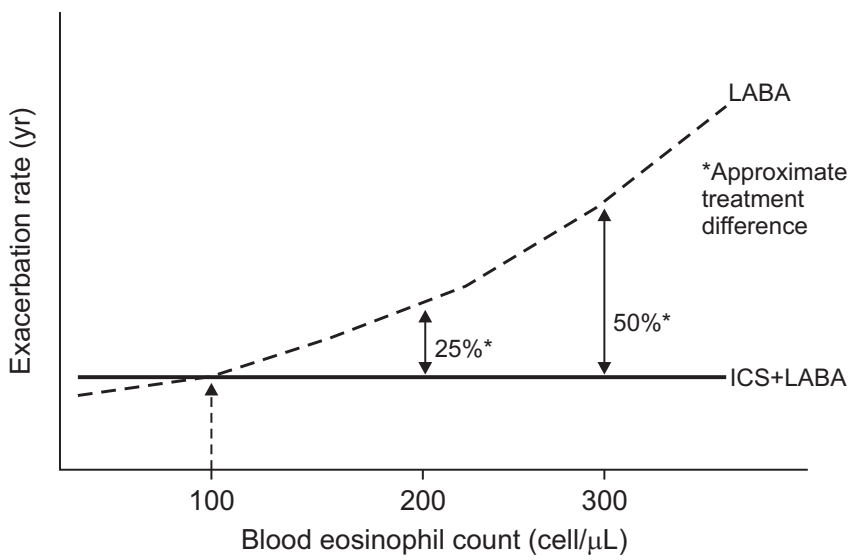

Figure 2. Representative illustration of the results of studies investigating the relationship between inhaled corticosteroid (ICS) effects (on exacerbations) and blood eosinophil counts. Effect sizes are estimates. Comparison shown is ICS/long-acting beta agonist (LABA) versus LABA; similar findings exist for ICS/LABA/long-acting muscarinic antagonist (LAMA) versus LABA/LAMA.

bation rate reduction observed at $>300$ eosinophils $/ \mu \mathrm{L}$, as shown in Figure 2. Interestingly, ICS benefits were lower in current smokers, with ICS benefits in this subgroup observed at a higher threshold, approximately $>200$ eosinophils $/ \mu \mathrm{L}$. A similar negative influence of current smoking on ICS effects was reported in the INCONTROL data modeling comparing ICS/LABA versus LABA ${ }^{27}$. The reduced effects of ICS in current smokers has not been consistently reported in COPD clinical trials and may be related to insufficient statistical power in previous subgroup analysis.

The TRIBUTE study compared triple therapy versus LABA/ LAMA $^{7}$, while the TRINITY study compared triple therapy versus LAMA ${ }^{6}$. These studies were conducted in patients with a history of exacerbations, and in both studies it was 
demonstrated that a single eosinophil threshold distinguished between patients with higher and lower ICS responses e.g., in TRINITY, eosinophils $\geq 2 \%$ or $\geq 200$ cells $/ \mu \mathrm{L}$ split the population into groups with approximately $>30 \%$ and $\leq 10 \%$ exacerbation rate reductions above and below these thresholds respectively. As already discussed, these single thresholds are not the optimum way to analyze the data. The KRONOS study evaluated triple therapy in a COPD population that included patients with and without a history of exacerbations ${ }^{31}$. Data modeling again showed the "continuous" relationship between blood eosinophil counts and ICS response, with no benefit observed at lower eosinophil counts and increasingly larger benefits at higher eosinophil counts.

\section{Blood Eosinophils, Exacerbation History, and ICS Response}

Two large studies have compared ICS/LABA versus LABA/ LAMA in patients with a history of exacerbations, with different outcomes on the prevention of moderate to severe exacerbations in the overall population; in the IMPACT study, ICS/ LABA had a greater effect than LABA/LAMA (10\% mean difference $)^{8}$, while the FLAME study reported that LAMA/LABA had a greater effect than ICS/LABA (17\% mean difference $)^{32}$. IMPACT data modeling showed a greater effect of ICS/LABA (compared to LAMA/LABA) at higher blood eosinophil counts ${ }^{30}$, while in the FLAME study the treatments appeared similar at higher blood eosinophil counts ${ }^{33}$. These studies enrolled populations with different levels of exacerbation risk; IMPACT included more patients with $\geq 2$ moderate exacerbations or $\geq 1$ severe exacerbation (hospitalization) in the previous year. This key difference appeared to increase the ICS effect (in patients with higher exacerbation risk) in IMPACT ${ }^{34}$. The predictive ability of blood eosinophils when comparing double combination inhalers therefore changes according to the exacerbation risk i.e., at higher eosinophil counts, any benefit of ICS/LABA over LAMA/LABA is more likely to be observed in patients at higher exacerbation risk. Other differences in the study designs of IMPACT and FLAME have been discussed and debated, such as differences in the run-in periods; previous treatment was continued during the run-in in IMPACT, while LAMA monotherapy was used in FLAME ${ }^{3,34}$. This led to ICS withdrawal in some patients at randomization in IMPACT but before run-in for all patients in FLAME. Regardless, the results of IMPACT and FLAME indicate that exacerbation risk and blood eosinophil counts interact to determine ICS response.

ICS withdrawal studies have demonstrated that exacerbations rates are greater in patients with higher blood eosinophil counts $^{35-37}$. Furthermore, higher eosinophil counts plus a history of $\geq 2$ exacerbations appears to identify individuals who are at the greatest risk of exacerbation after ICS withdrawa ${ }^{37}$.
The concept of ICS withdrawal in clinical practice has gained popularity in recent years, due to concerns about ICS side effects and a confidence that many patients can be treated successfully with LABA/LAMA combination inhalers without the need for additional ICS treatment. However, these ICS withdrawal studies indicate that this strategy has increased risk in patients with higher blood eosinophil counts $(>300 \text { cells } / \mu \mathrm{L})^{3}$. Furthermore, these ICS withdrawal studies were performed mainly in patients with 0 or 1 exacerbation in the previous year $^{35,38}$, but in the subgroup with $\geq 2$ exacerbations there appeared to be the greatest risk ${ }^{37}$. Again, these data highlight that blood eosinophil counts and exacerbation risk both influence ICS response.

Real word data analysis, using UK primary care information, reported that the effectiveness of triple therapy compared to LABA/LAMA was greater in patients with more exacerbations or higher blood eosinophils ${ }^{39}$. These real world data compliment the RCT data already reviewed.

\section{Blood Eosinophil Count Stability}

The intra-class correlation coefficient (ICC) for repeated blood eosinophil counts in COPD patients has been reported to be $0.64-0.89$ in studies with follow up ranging from 3 months to 5 years ${ }^{40-44}$. ICC values $>0.75$ are interpreted as showing excellent correlation ${ }^{41}$. On one hand, it has been noted that these ICC values are similar to other biomarkers used in clinical practice such as cholesterol or glycated hemoglobin ${ }^{3}$, supporting the case for using blood eosinophil counts in clinical practice. On the other hand, concerns have been expressed that blood eosinophil counts may show excessive variability, limiting their clinical usefulness ${ }^{45}$.

It is worth dissecting published data in detail in order to understand eosinophil stability properly. A recent publication investigating stability $(\mathrm{n}=225)$ using the categories $<100$, 100 to $<300$ and $\geq 300$ eosinophils/ $\mu$ L showed that $69.3 \%$ of COPD patients remained in the same category after 1 year $^{41}$. Importantly, movement from one category to an adjacent category was more likely in patients with eosinophil measurements close to the threshold value, suggesting that movement between categories was more related to natural measurement variation rather than altered disease pathophysiology. GOLD 2020 recommends the use of $<100$ cells $/ \mu \mathrm{L}$ and $>300$ cells/ $\mu \mathrm{L}$ thresholds, but cautions that these are "estimates, rather than precise cut-off values" for predicting ICS effects ${ }^{46}$. Previous criticisms of blood eosinophil count stability have focused on the re-categorization of patients due to movement across thresholds ${ }^{45}$, but a more practical approach (as advocated by GOLD) is needed when the numerical changes are small; for example, moving from just below to just above the 300 eosinophils/ $\mu \mathrm{L}$ threshold does not change the clinical interpretation (namely, that there is increased likelihood of ICS benefit). 
This one year stability study ${ }^{41}$ and a different study with follow up from $2-5$ years $(n=59)^{40}$ both showed that the repeatability coefficients were lower (i.e., less numerical variation) in patients with lower blood eosinophil counts. Small changes in these patients may cause movement across a threshold value (e.g., 100 eosinophils $/ \mu \mathrm{L}$ ). However, as already discussed, it is important to understand that the clinical prediction of ICS response is unlikely to be altered by a small numerical change. Individuals with higher blood eosinophil counts ( $>300$ cells/ $\mu \mathrm{L}$ ) have more numerical variation, but again this may not result in any change in clinical interpretation, e.g., a change from 500 to 250 cells $/ \mu \mathrm{L}$ still suggests that the patient is more likely to derive benefit from ICS treatment.

Studies of blood eosinophil stability have used various thresholds, with some studies using percentage eosinophil counts rather than absolute numbers ${ }^{21}$. Percentage counts are clearly influenced by the presence of other immune cells, and the field has now moved towards using absolute numbers to more accurately define the degree of eosinophilic inflammation.

\section{Blood Eosinophils and Clinical Outcomes}

Numerous cohort studies have investigated associations between blood eosinophil counts and clinical features or outcomes ${ }^{18,21,45,47-49}$. In particular, there has been interest in whether blood eosinophil counts are associated with either exacerbation rates or mortality. The results of these studies have been inconsistent, and it is reasonable to conclude that blood eosinophil counts should not be routinely used in clinical practice as a prognostic biomarker for events such as exacerbations and mortality.

The RCTs already reviewed that were conducted in COPD patients with a history of exacerbations showed an association between higher blood eosinophil counts and increased exacerbation rates in the treatment arms without ICS (Figure $2)^{27-30}$. These data suggest that blood eosinophil are a prognostic biomarker in patients with both (1) a history of exacerbations and (2) receiving no ICS treatment. These RCTs showed no relationship between blood eosinophil counts and exacerbation rates in patients treated with ICS, as these drugs modify exacerbation risk in an eosinophil dependent manner. These observations provide the explanation for the lack of association between blood eosinophil counts and exacerbations in observational cohort studies, which include many patients with (1) no prior exacerbation history and/or (2) taking ICS treatment. Despite these limiting factors, some large cohort studies have still found that patients with a history of $\geq 2 \mathrm{ex}$ acerbations plus higher blood eosinophil counts have more exacerbations at during follow-up ${ }^{47}$.

\section{Blood Eosinophils, Type 2 Inflammation, and Microbiome}

The mechanistic explanation for the association between higher blood eosinophil counts and increased ICS response in COPD patients has not been definitively elucidated. Nevertheless, there are pieces of evidence that provide insights. The bronchoscopy study by Kolsum et al. ${ }^{14}$ showed that higher blood eosinophil counts are associated with increased eosinophilic airway inflammation, greater reticular basement membrane thickening, and increased levels of the T2 cytokines IL-5 and eotaxin-2; these pathophysiological features are also found in patients with asthma ${ }^{50,51}$. However, this study excluded individuals with a history of asthma or atopy. It has also been shown that T2 gene expression in COPD bronchial biopsies is associated with lung and blood eosinophil counts ${ }^{52}$. Overall, eosinophilic airway inflammation seems to be associated with a wider profile of $\mathrm{T} 2$ inflammation; T2 inflammation is known to be corticosteroid sensitive in asthma ${ }^{53}$, and probably the same situation exists in COPD patients.

The asthma-COPD overlap (ACO) describes a group of individuals with clinical features found in both conditions ${ }^{54,55}$. While "eosinophilic COPD" shares some pathological features with asthma, there is no added value in labeling these patients as ACO, as ACO is a broad label encompassing different clinical phenotypes. Referring to these patients as "eosinophilic COPD" or "COPD with higher blood eosinophil counts" is a more precise description of this COPD subset than using ACO which also includes (multiple) other subtypes.

It has been observed that higher sputum eosinophil counts are associated with lower levels of colonizing bacteria in the airways of COPD patients ${ }^{56,57}$. Furthermore, a longitudinal observational study reported that blood eosinophil counts $<100$ cells $/ \mu \mathrm{L}$ were associated with increased probability of chronic bacterial airway infection and pneumonia ${ }^{58}$. These findings suggest that susceptibility to bacterial airway infection is increased in COPD patients with lower eosinophil counts, but the mechanisms to explain these findings have not been defined ${ }^{59}$. Eosinophils have no direct anti-bacterial activity against common pathogens that infect COPD patients ${ }^{60}$. Therefore, it is likely that there are other differences in antimicrobial host defence associated with eosinophil numbers. Interestingly, low sputum eosinophil counts in COPD patients have been associated with reduced bacterial diversity and increased Proteobacteria including haemophilus ${ }^{61,62}$. Overall, these studies show both increased bacterial load and altered microbiome profiles in patients with lower eosinophil counts.

The presence of bacterial infection promotes neutrophilic airway inflammation ${ }^{56,62,63}$. ICS have limited effects on neutrophilic airway inflammation in humans $s^{64-66}$. It therefore appears that COPD patients with low eosinophil counts are more likely to skew towards bacterial infection and neutrophilic inflammation that responds poorly to ICS treatment. In contrast, 
high eosinophil counts, associated with increased T2 gene expression and a lower burden of bacterial infection, is a profile of airway inflammation that is more ICS sensitive; this model to explain the relationships between eosinophils, bacteria and ICS response are shown in Figure 3.

It is relevant to consider whether ICS are targeting eosinophils themselves, and/or other aspects of inflammation associated with higher eosinophil counts. An RCT using sputum eosinophils to predict ICS effects showed improvements in $\mathrm{FEV}_{1}$ in COPD patients with higher eosinophil counts, but no reduction in eosinophil counts ${ }^{25}$. In contrast, ICS/LABA reduced sputum eosinophil counts compared to placebo, in addition to suppression of lymphocytes and mast cells numbers in the bronchial mucosa ${ }^{65}$. There was no reduction in sputum neutrophil numbers. Another bronchoscopy study in COPD patients also showed an effect of ICS treatment on submucosal lymphocytes, but no effect on neutrophils and eosinophils $^{66}$. These studies have provided consistent evidence that ICS reduce airway lymphocyte numbers and have no effect on neutrophil counts, but the results for eosinophils have been mixed. This mixed evidence can be interpreted as showing that ICS can reduce airway eosinophil numbers, but that this finding is not consistent in all patients. This may be due to low baseline eosinophil numbers in some patients. Alternatively, the therapeutic benefit of ICS in eosinophilic COPD patients may be due to pharmacological effects on inflammation components (T2 inflammation) beyond the eosinophil cell.

RCTs investigating the effects of monoclonal antibodies targeting IL-5, conducted in COPD patients with a history of exacerbations, have reported both positive and negative results for the effect on exacerbation rate reduction ${ }^{67,68}$. A prespecified combined analyses of the GALATHEA and TERRANOVA studies of benralizumab (which targets IL-5 receptor alpha) demonstrated that the greatest treatment benefit

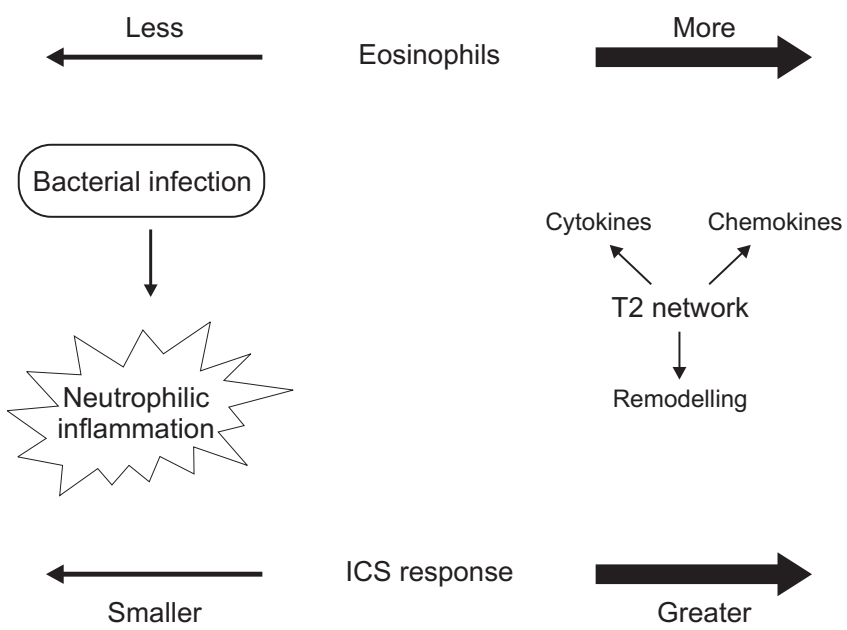

Figure 3. Relationships between eosinophilic inflammation, microbiome and inhaled corticosteroid (ICS) response. was observed in the subgroup receiving triple therapy with blood eosinophil counts $\geq 220$ cells $/ \mu \mathrm{L}$ and $\geq 3$ exacerbations in the prior year ${ }^{69}$. These findings highlight that significant eosinophilic inflammation, which may respond to monoclonal antibody targeting, can persist despite ICS treatment.

Studies focused on COPD exacerbations have found that blood and sputum eosinophil counts are increased in a subset of patients during exacerbations ${ }^{70}$. Interestingly, higher blood eosinophil counts in the stable state are associated with an increased probability of exacerbations with increased sputum eosinophil numbers ${ }^{71}$. This association between eosinophils in the stable and exacerbation states suggests that ICS treatment probably suppresses exacerbation subtypes involving increased eosinophilic inflammation.

\section{GOLD 2019 and Blood Eosinophils}

The evidence already reviewed formed the basis of the GOLD 2019 recommendations to use blood eosinophil counts as a biomarker to help direct ICS treatment in COPD patients with a history of exacerbations ${ }^{3}$. These recommendations combine clinical information (exacerbation risk) with biological data (blood eosinophils) as a precision medicine approach in order to optimize the potential for benefit over risk.

The FLAME and IMPACT studies reported different results for the comparison of the effects of ICS/LABA versus LABA/ LAMA combinations on exacerbation rates ${ }^{8,32}$. A major reason for these divergent results was the different exacerbations risks of the study populations ${ }^{34}$. Accordingly, GOLD states that the benefits of ICS are likely to be greater in high exacerbation risk patients with a history of $\geq 2$ moderate exacerbations and/ or $\geq 1$ severe exacerbation in the previous year compared to patients with 1 moderate exacerbation ${ }^{3}$. Other clinical factors relevant to the use of ICS include a history of asthma, which favors ICS use, and risk factors for ICS side effects, such as repeated pneumonia, which argue against ICS use ${ }^{72}$. All of this clinical information should be collected and then used alongside blood eosinophil counts in order to make optimal decisions for each individual.

GOLD uses thresholds of $>300$ eosinophils $/ \mu \mathrm{L}$ and $<100$ eosinophils $/ \mu \mathrm{L}$ to identify individuals with a higher and lower probability, respectively, of experiencing treatment benefit with ICS $^{46}$. The GOLD 2020 revision states that these are "estimates, rather than precise cut-off values ${ }^{\prime \prime 6}$. The purpose of this statement is highlight that small numerical changes in blood eosinophil counts should not lead to a change in ICS treatment, even if the change leads to movement across a threshold value.

Some clinicians have focused on the $>300$ eosinophils $/ \mu \mathrm{L}$ threshold stated in GOLD, preferring to use ICS only in these individuals. However, this approach does not account for the 
possibility of a treatment benefit that has been observed in patients with 100-300 eosinophils/ $\mu \mathrm{L}^{3,30}$. GOLD does not include recommendations concerning eosinophils and current smoking, but there is now evidence that current smoking reduces corticosteroid sensitivity ${ }^{27,30}$. This means that ICS benefits are less likely in current smokers, and that greater ICS benefits may be observed at lower blood eosinophil counts in ex-smokers (i.e., $<100$ eosinophils $/ \mu \mathrm{L}$ ).

\section{Conclusion}

Blood eosinophil counts are being increasingly used in clinical practice to support clinical decision making regarding ICS use. GOLD recommendations focus on integrating clinical information with eosinophil counts to optimize the choice of combination inhaler to be used for exacerbation prevention $^{3}$. Eosinophilic COPD patients appear to have a wider profile of $\mathrm{T} 2$ inflammation, which may provide the mechanistic explanation for the increasing benefit of ICS at higher blood eosinophil counts. Emerging data indicate that lower blood eosinophil counts are associated with increased risk of chronic bacterial infection. Complex relationships appear to exist between eosinophil counts, ICS response, and the airway microbiome. Understanding this complexity is the key to optimizing current pharmacological management and developing novel drugs for the future.

\section{Conflicts of Interest}

Dave Singh reports personal fees from Cipla, Genentech, Peptinnovate, AstraZeneca, Boehringer Ingelheim, Chiesi Farmaceutici, GlaxoSmithKline, Glenmark, Menarini, Novartis, Pfizer, Pulmatrix, Teva, Theravance, and Verona.

\section{Funding}

Dave Singh is supported by the National Institute for Health Research (NIHR) Manchester Biomedical Research Centre (BRC).

\section{References}

1. Vogelmeier CF, Criner GJ, Martinez FJ, Anzueto A, Barnes PJ, Bourbeau J, et al. Global strategy for the diagnosis, management, and prevention of chronic obstructive lung disease 2017 report: GOLD executive summary. Eur Respir J 2017;49:1700214.

2. Singh D, Roche N, Halpin D, Agusti A, Wedzicha JA, Martinez FJ. Current controversies in the pharmacological treatment of chronic obstructive pulmonary disease. Am J Respir Crit Care Med 2016;194:541-9.

3. Singh D, Agusti A, Anzueto A, Barnes PJ, Bourbeau J, Celli $\mathrm{BR}$, et al. Global strategy for the diagnosis, management, and prevention of chronic obstructive lung disease: the GOLD science committee report 2019. Eur Respir J 2019;53:1900164.

4. Singh D, Corradi M, Spinola M, Petruzzelli S, Papi A. Extrafine beclometasone diproprionate/formoterol fumarate: a review of its effects in chronic obstructive pulmonary disease. NPJ Prim Care Respir Med 2016;26:16030.

5. Singh D, Papi A, Corradi M, Pavlisova I, Montagna I, Francisco $\mathrm{C}$, et al. Single inhaler triple therapy versus inhaled corticosteroid plus long-acting beta2-agonist therapy for chronic obstructive pulmonary disease (TRILOGY): a double-blind, parallel group, randomised controlled trial. Lancet 2016;388:96373.

6. Vestbo J, Papi A, Corradi M, Blazhko V, Montagna I, Francisco $\mathrm{C}$, et al. Single inhaler extrafine triple therapy versus longacting muscarinic antagonist therapy for chronic obstructive pulmonary disease (TRINITY): a double-blind, parallel group, randomised controlled trial. Lancet 2017;389:1919-29.

7. Papi A, Vestbo J, Fabbri L, Corradi M, Prunier H, Cohuet G, et al. Extrafine inhaled triple therapy versus dual bronchodilator therapy in chronic obstructive pulmonary disease (TRIBUTE): a double-blind, parallel group, randomised controlled trial. Lancet 2018;391:1076-84.

8. Lipson DA, Barnhart F, Brealey N, Brooks J, Criner GJ, Day $\mathrm{NC}$, et al. Once-daily single-inhaler triple versus dual therapy in patients with COPD. N Engl J Med 2018;378:1671-80.

9. Hurst JR, Vestbo J, Anzueto A, Locantore N, Mullerova H, TalSinger R, et al. Susceptibility to exacerbation in chronic obstructive pulmonary disease. N Engl J Med 2010;363:1128-38.

10. Esnault S, Kelly EA. Essential mechanisms of differential activation of eosinophils by IL-3 compared to GM-CSF and IL-5. Crit Rev Immunol 2016;36:429-44.

11. Rutgers SR, Timens W, Kaufmann HF, van der Mark TW, Koeter GH, Postma DS. Comparison of induced sputum with bronchial wash, bronchoalveolar lavage and bronchial biopsies in COPD. Eur Respir J 2000;15:109-15.

12. Saha S, Brightling CE. Eosinophilic airway inflammation in COPD. Int J Chron Obstruct Pulmon Dis 2006;1:39-47.

13. Kolsum U, Southworth T, Jackson N, Singh D. Blood eosinophil counts in COPD patients compared to controls. Eur Respir J 2019;54:1900633.

14. Kolsum U, Damera G, Pham TH, Southworth T, Mason S, Karur P, et al. Pulmonary inflammation in patients with chronic obstructive pulmonary disease with higher blood eosinophil counts. J Allergy Clin Immunol 2017;140:1181-4.

15. Fahy JV. Type 2 inflammation in asthma--present in most, absent in many. Nat Rev Immunol 2015;15:57-65.

16. Bush A. How early do airway inflammation and remodeling occur? Allergol Int 2008;57:11-9.

17. Kolsum U, Ravi A, Hitchen P, Maddi S, Southworth T, Singh D. 
Clinical characteristics of eosinophilic COPD versus COPD patients with a history of asthma. Respir Res 2017;18:73.

18. Hastie AT, Martinez FJ, Curtis JL, Doerschuk CM, Hansel NN, Christenson S, et al. Association of sputum and blood eosinophil concentrations with clinical measures of COPD severity: an analysis of the SPIROMICS cohort. Lancet Respir Med 2017;5:956-67.

19. Bafadhel M, McKenna S, Pickering S, Reid C, Mistry V, Rugman $\mathrm{P}$, et al. The sensitivity and specificity of peripheral blood eosinophilia to predict sputum eosinophilia in COPD subjects. Am J Respir Crit Care Med 2009;179:A1479.

20. Pignatti P, Visca D, Cherubino F, Zampogna E, Lucini E, Saderi L, et al. Do blood eosinophils strictly reflect airway inflammation in COPD? Comparison with asthmatic patients. Respir Res 2019;20:145.

21. Singh D, Kolsum U, Brightling CE, Locantore N, Agusti A, TalSinger R, et al. Eosinophilic inflammation in COPD: prevalence and clinical characteristics. Eur Respir J 2014;44:1697700 .

22. Negewo NA, McDonald VM, Baines KJ, Wark PA, Simpson JL, Jones PW, et al. Peripheral blood eosinophils: a surrogate marker for airway eosinophilia in stable COPD. Int J Chron Obstruct Pulmon Dis 2016;11:1495-504.

23. Eltboli O, Mistry V, Barker B, Brightling CE. Relationship between blood and bronchial submucosal eosinophilia and reticular basement membrane thickening in chronic obstructive pulmonary disease. Respirology 2015;20:667-70.

24. Turato G, Semenzato U, Bazzan E, Biondini D, Tine M, Torrecilla $\mathrm{N}$, et al. Blood eosinophilia neither reflects tissue eosinophils nor worsens clinical outcomes in chronic obstructive pulmonary disease. Am J Respir Crit Care Med 2018;197: 1216-9.

25. Brightling CE, McKenna S, Hargadon B, Birring S, Green $\mathrm{R}$, Siva R, et al. Sputum eosinophilia and the short term response to inhaled mometasone in chronic obstructive pulmonary disease. Thorax 2005;60:193-8.

26. Brightling CE, Monteiro W, Ward R, Parker D, Morgan MD, Wardlaw AJ, et al. Sputum eosinophilia and short-term response to prednisolone in chronic obstructive pulmonary disease: a randomised controlled trial. Lancet 2000;356:14805.

27. Bafadhel M, Peterson S, De Blas MA, Calverley PM, Rennard SI, Richter K, et al. Predictors of exacerbation risk and response to budesonide in patients with chronic obstructive pulmonary disease: a post-hoc analysis of three randomised trials. Lancet Respir Med 2018;6:117-26.

28. Pascoe S, Locantore N, Dransfield MT, Barnes NC, Pavord ID. Blood eosinophil counts, exacerbations, and response to the addition of inhaled fluticasone furoate to vilanterol in patients with chronic obstructive pulmonary disease: a secondary analysis of data from two parallel randomised controlled trials. Lancet Respir Med 2015;3:435-42.

29. Siddiqui SH, Guasconi A, Vestbo J, Jones P, Agusti A, Pag- giaro P, et al. Blood eosinophils: a biomarker of response to extrafine beclomethasone/formoterol in chronic obstructive pulmonary disease. Am J Respir Crit Care Med 2015;192:5235.

30. Pascoe S, Barnes N, Brusselle G, Compton C, Criner GJ, Dransfield MT, et al. Blood eosinophils and treatment response with triple and dual combination therapy in chronic obstructive pulmonary disease: analysis of the IMPACT trial. Lancet Respir Med 2019;7:745-56.

31. Ferguson GT, Rabe KF, Martinez FJ, Fabbri LM, Wang C, Ichinose M, et al. Triple therapy with budesonide/glycopyrrolate/ formoterol fumarate with co-suspension delivery technology versus dual therapies in chronic obstructive pulmonary disease (KRONOS): a double-blind, parallel-group, multicentre, phase 3 randomised controlled trial. Lancet Respir Med 2018;6:747-58.

32. Wedzicha JA, Banerji D, Chapman KR, Vestbo J, Roche N, Ayers RT, et al. Indacaterol-glycopyrronium versus salmeterol-fluticasone for COPD. N Engl J Med 2016;374:2222-34.

33. Roche N, Chapman KR, Vogelmeier CF, Herth FJF, Thach $\mathrm{C}$, Fogel $\mathrm{R}$, et al. Blood eosinophils and response to maintenance chronic obstructive pulmonary disease treatment: data from the FLAME Trial. Am J Respir Crit Care Med 2017;195: 1189-97.

34. Singh D. Double combination inhalers in COPD: how to get your head around this data. Respirology 2018;23:1088-9.

35. Chapman KR, Hurst JR, Frent SM, Larbig M, Fogel R, Guerin $\mathrm{T}$, et al. Long-term triple therapy de-escalation to indacaterol/glycopyrronium in patients with chronic obstructive pulmonary disease (SUNSET): a randomized, doubleblind, triple-dummy clinical trial. Am J Respir Crit Care Med 2018;198:329-39.

36. Watz H, Tetzlaff K, Wouters EF, Kirsten A, Magnussen H, Rodriguez-Roisin R, et al. Blood eosinophil count and exacerbations in severe chronic obstructive pulmonary disease after withdrawal of inhaled corticosteroids: a post-hoc analysis of the WISDOM trial. Lancet Respir Med 2016;4:390-8.

37. Calverley PM, Tetzlaff K, Vogelmeier C, Fabbri LM, Magnussen $\mathrm{H}$, Wouters EF, et al. Eosinophilia, frequent exacerbations, and steroid response in chronic obstructive pulmonary disease. Am J Respir Crit Care Med 2017;196:1219-21.

38. Magnussen H, Disse B, Rodriguez-Roisin R, Kirsten A, Watz $\mathrm{H}$, Tetzlaff K, et al. Withdrawal of inhaled glucocorticoids and exacerbations of COPD. N Engl J Med 2014;371:1285-94.

39. Voorham J, Corradi M, Papi A, Vogelmeier CF, Singh D, Fabbri LM, et al. Comparative effectiveness of triple therapy versus dual bronchodilation in COPD. ERJ Open Res 2019;5:001062019.

40. Southworth T, Beech G, Foden P, Kolsum U, Singh D. The reproducibility of COPD blood eosinophil counts. Eur Respir J 2018;52:1800427.

41. Long GH, Southworth T, Kolsum U, Donaldson GC, Wedzicha JA, Brightling CE, et al. The stability of blood eosino- 
phils in chronic obstructive pulmonary disease. Respir Res 2020;21:15.

42. Barker B, Mistry V, Pancholi M, Brightling C, Bafadhel M. P210: are sputum and blood biomarkers of inflammation repeatable in stable COPD? Thorax 2012;67:A155-6.

43. Landis SH, Suruki R, Hilton E, Compton C, Galwey NW. Stability of blood eosinophil count in patients with COPD in the UK clinical practice research datalink. COPD 2017;14:382-8.

44. Bafadhel M, Pavord ID, Russell RE. Eosinophils in COPD: just another biomarker? Lancet Respir Med 2017;5:747-59.

45. Casanova C, Celli BR, de-Torres JP, Martinez-Gonzalez C, Cosio BG, Pinto-Plata V, et al. Prevalence of persistent blood eosinophilia: relation to outcomes in patients with COPD. Eur Respir J 2017;50:1701162.

46. Global Initiative for Chronic Obstructive Lung Disease. Global strategy for the diagnosis, management and prevention of chronic obstructive pulmonary disease [Internet]. Fontana, WI: The Global Initiative for Chronic Obstructive Lung Disease; 2020 [cited 2020 Jan 10]. Available from: http:// www.goldcopd.org/guidelines-global-strategy-for-diagnosismanagement.html.

47. Yun JH, Lamb A, Chase R, Singh D, Parker MM, Saferali A, et al. Blood eosinophil count thresholds and exacerbations in patients with chronic obstructive pulmonary disease. J Allergy Clin Immunol 2018;141:2037-47.

48. Vedel-Krogh S, Nielsen SF, Lange P, Vestbo J, Nordestgaard BG. Blood eosinophils and exacerbations in chronic obstructive pulmonary disease. The Copenhagen General Population Study. Am J Respir Crit Care Med 2016;193:965-74.

49. DiSantostefano RL, Hinds D, Le HV, Barnes NC. Relationship between blood eosinophils and clinical characteristics in a cross-sectional study of a US population-based COPD cohort. Respir Med 2016;112:88-96.

50. Coleman JM, Naik C, Holguin F, Ray A, Ray P, Trudeau JB, et al. Epithelial eotaxin-2 and eotaxin-3 expression: relation to asthma severity, luminal eosinophilia and age at onset. Tho$\operatorname{rax} 2012 ; 67: 1061-6$.

51. Flood-Page P, Menzies-Gow A, Phipps S, Ying S, Wangoo A, Ludwig MS, et al. Anti-IL-5 treatment reduces deposition of ECM proteins in the bronchial subepithelial basement membrane of mild atopic asthmatics. J Clin Invest 2003;112:102936.

52. Christenson SA, Steiling K, van den Berge M, Hijazi K, Hiemstra PS, Postma DS, et al. Asthma-COPD overlap. Clinical relevance of genomic signatures of type 2 inflammation in chronic obstructive pulmonary disease. Am J Respir Crit Care Med 2015;191:758-66.

53. Woodruff PG, Modrek B, Choy DF, Jia G, Abbas AR, Ellwanger A, et al. T-helper type 2-driven inflammation defines major subphenotypes of asthma. Am J Respir Crit Care Med 2009; 180:388-95.

54. Bateman ED, Reddel HK, van Zyl-Smit RN, Agusti A. The asthma-COPD overlap syndrome: towards a revised taxonomy of chronic airways diseases? Lancet Respir Med 2015;3:719-28.

55. Maselli DJ, Hardin M, Christenson SA, Hanania NA, Hersh CP, Adams SG, et al. Clinical approach to the therapy of asthmaCOPD overlap. Chest 2019;155:168-77.

56. Kolsum U, Donaldson GC, Singh R, Barker BL, Gupta V, George L, et al. Blood and sputum eosinophils in COPD; relationship with bacterial load. Respir Res 2017;18:88.

57. Contoli M, Pauletti A, Rossi MR, Spanevello A, Casolari P, Marcellini A, et al. Long-term effects of inhaled corticosteroids on sputum bacterial and viral loads in COPD. Eur Respir J 2017;50:1700451.

58. Martinez-Garcia MA, Faner R, Oscullo G, la Rosa-Carrillo D, Soler-Cataluna JJ, Ballester M, et al. Inhaled steroids, circulating eosinophils, chronic airway infection and pneumonia risk in chronic obstructive pulmonary disease: a network analysis. Am J Respir Crit Care Med 2020 Jan 10 [Epub]. https://doi. org/10.1164/rccm.201908-1550OC.

59. Dransfield MT, Singh D. Predicting pneumonia in COPD: have we unraveled the network of risks? Am J Respir Crit Care Med 2020 Feb 3 [Epub]. https://doi.org/10.1164/rccm. 202001-0132ED.

60. George L, Wright A, Mistry V, Sutcliffe A, Chachi L, Haldar $\mathrm{K}$, et al. Sputum Streptococcus pneumoniae is reduced in COPD following treatment with benralizumab. Int J Chron Obstruct Pulmon Dis 2019;14:1177-85.

61. Wang Z, Bafadhel M, Haldar K, Spivak A, Mayhew D, Miller $\mathrm{BE}$, et al. Lung microbiome dynamics in COPD exacerbations. Eur Respir J 2016;47:1082-92.

62. Ghebre MA, Pang PH, Diver S, Desai D, Bafadhel M, Haldar $\mathrm{K}$, et al. Biological exacerbation clusters demonstrate asthma and chronic obstructive pulmonary disease overlap with distinct mediator and microbiome profiles. J Allergy Clin Immunol 2018;141:2027-36.

63. Wang Z, Maschera B, Lea S, Kolsum U, Michalovich D, Van Horn S, et al. Airway host-microbiome interactions in chronic obstructive pulmonary disease. Respir Res 2019;20:113.

64. Singh D, Siew L, Christensen J, Plumb J, Clarke GW, Greenaway S, et al. Oral and inhaled p38 MAPK inhibitors: effects on inhaled LPS challenge in healthy subjects. Eur J Clin Pharmacol 2015;71:1175-84.

65. Barnes NC, Qiu YS, Pavord ID, Parker D, Davis PA, Zhu J, et al. Antiinflammatory effects of salmeterol/fluticasone propionate in chronic obstructive lung disease. Am J Respir Crit Care Med 2006;173:736-43.

66. Bourbeau J, Christodoulopoulos P, Maltais F, Yamauchi Y, Olivenstein R, Hamid Q. Effect of salmeterol/fluticasone propionate on airway inflammation in COPD: a randomised controlled trial. Thorax 2007;62:938-43.

67. Criner GJ, Celli BR, Brightling CE, Agusti A, Papi A, Singh D, et al. Benralizumab for the prevention of COPD Exacerbations. N Engl J Med 2019;381:1023-34.

68. Pavord ID, Chanez P, Criner GJ, Kerstjens HA, Korn S, Lugogo $\mathrm{N}$, et al. Mepolizumab for eosinophilic chronic obstructive 
pulmonary disease. N Engl J Med 2017;377:1613-29.

69. Criner GJ, Celli BR, Singh D, Agusti A, Papi A, Jison M, et al. Predicting response to benralizumab in chronic obstructive pulmonary disease: analyses of GALATHEA and TERRANOVA studies. Lancet Respir Med 2020;8:158-70.

70. Bafadhel M, McKenna S, Terry S, Mistry V, Reid C, Haldar P, et al. Acute exacerbations of chronic obstructive pulmonary disease: identification of biologic clusters and their biomarkers.
Am J Respir Crit Care Med 2011;184:662-71.

71. Mayhew D, Devos N, Lambert C, Brown JR, Clarke SC, Kim VL, et al. Longitudinal profiling of the lung microbiome in the AERIS study demonstrates repeatability of bacterial and eosinophilic COPD exacerbations. Thorax 2018;73:422-30.

72. Agusti A, Fabbri LM, Singh D, Vestbo J, Celli B, Franssen FM, et al. Inhaled corticosteroids in COPD: friend or foe? Eur Respir J 2018;52:1801219. 